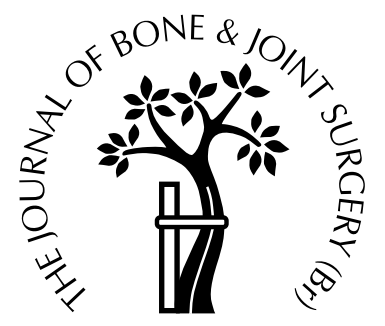

\title{
The anatomy of the iliolumbar vein
}

\author{
A CADAVER STUDY
}

Vinay Jasani, David Jaffray

From the Robert Jones and Agnes Hunt Hospital, Oswestry, England

W e carried out a cadaver study of 16 iliolumbar veins in order to define the surgical anatomy. Two variants were found; a single vein at a mean distance of $3.74 \mathrm{~cm}$ from the inferior vena cava (11 of 16) and two separate draining veins at a mean distance from the vena cava of $2.98 \mathrm{~cm}$ for the proximal and $6.24 \mathrm{~cm}$ for the distal stem (5 of 16). Consistently, the proximal vein tore on attempted medial retraction of the great vessels. The mean length of the vein was $1.6 \mathrm{~cm}$ and its mean width $1.07 \mathrm{~cm}$. Three stems were shorter than $0.5 \mathrm{~cm}$. Two or more tributaries usually drained the iliacus and psoas muscles, and the fifth lumbar vertebral body. The obturator nerve crossed all veins superficially at a mean of $2.76 \mathrm{~cm}$ lateral to the mouth. In four of these, this distance was less than $1.5 \mathrm{~cm}$. Usually, the lumbosacral trunk crossed deep, at a mean distance of $2.5 \mathrm{~cm}$ lateral to the mouth, but in three veins, this distance was $1 \mathrm{~cm}$ or less.

Our findings emphasise the need for proper dissection of the iliolumbar vein before ligature during exposure of the anterior lumbar spine.

J Bone Joint Surg [Br] 2002;84-B:1046-9.

Received 30 January 2002; Acccepted 25 March 2002

The iliolumbar vein must be identified during anterior surgery to the lower lumbar spine. ${ }^{1-7}$ It is described as draining the lower lumbar region into the common iliac vein and is thought to be the segmental equivalent for the fifth lumbar vertebra. ${ }^{8-13}$ The vein is usually encountered

V. Jasani, FRCS Orth, Specialist Registrar in Orthopaedics and Trauma North Staffordshire Royal Infirmary, Princess Road, Stoke-on-Trent, Staffordshire ST4 7LN, UK.

D. Jaffray, FRCS, Consultant Spinal Surgeon

Robert Jones and Agnes Hunt Hospital, Oswestry, Shropshire SY10 7AG, UK.

Correspondence should be sent to Mr V. Jasani at 3 Bannacks Close, Willaston, Nantwich, Cheshire CW5 6RP, UK.

(C)2002 British Editorial Society of Bone and Joint Surgery 0301-620X/02/713195\$2.00 when exposing the lumbosacral junction and the L4/L5 interspace during mobilisation of the great vessels. ${ }^{1-7}$

Inadvertent disruption of this vessel can lead to massive haemorrhage. ${ }^{14-16}$ Most authors advocate formal dissection and control of the vessel early in the exposure either by ligation and division or electrocautery. ${ }^{1-7}$

Although well known as a structure of particular significance, little is known about the detailed anatomy and function of the iliolumbar vein. ${ }^{1-13,17}$ Our aim was to describe this, and to identify the structures drained by the vein and its relationship to nearby structures.

\section{Materials and Methods}

We dissected 16 iliolumbar veins from eight intact formaldehyde-preserved cadavers. The presence of the veins was noted, the pattern of drainage, their dimensions, the points of confluence with the common iliac vein, the obliquity of the vein and its relationship to nearby structures. An assessment of the risk of avulsion was made for each vein, by medially retracting the great vessels in order to expose the L4/L5 disc space bilaterally.

\section{Results}

An iliolumbar drainage system was present in all 16 dissections. The mean distance from the inferior vena cava to the iliolumbar vein overall was $3.5 \mathrm{~cm}$. The mean distance on the right side was $3.01 \mathrm{~cm}$ and on the left $3.99 \mathrm{~cm}$.

Two main variants were found. In 11 dissections, there was a single vein draining into the common iliac vein (Fig. 1). In all examples this vein tore on retracting the great vessels medially for exposure of the L4/L5 disc space. The mean distance from the inferior vena cava to the single iliolumbar vein was $3.74 \mathrm{~cm}$ (2.0 to 5.0). In five dissections (3 right, 2 left), the iliolumbar system consisted of two veins draining into the common iliac vein (Figs 2 and 8). In all, the most proximal vein was at risk of tearing on retraction for exposure of the disc space. The mean distance from the inferior vena cava to the proximal tributary was $2.98 \mathrm{~cm}(2.0$ to 4.2$)$ and to the distal tributary $6.24 \mathrm{~cm}(5.0$ to 8.2 ), which was a mean of $3.26 \mathrm{~cm}$ (2.0 to 4.5$)$ beyond the first tributary (Fig. 2). The distal or accessory vein never tore on retraction of the great vessels. 


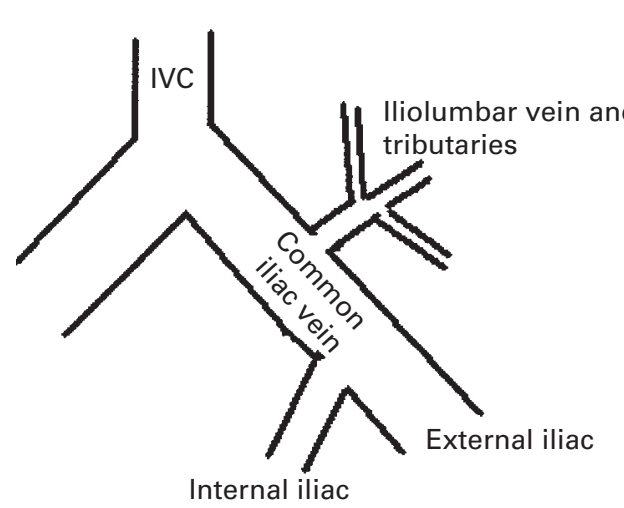

Fig. 1

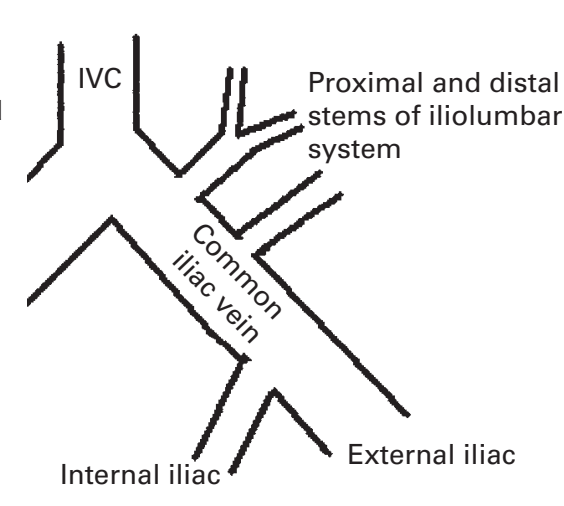

Fig. 2

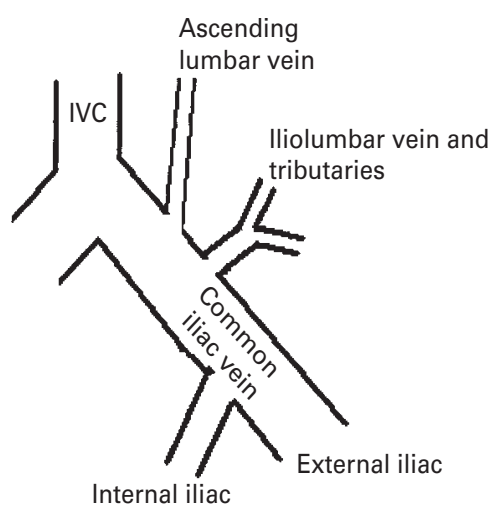

Fig. 3

Figure 1 -- Diagram of the iliolumbar system with one main stem only. The uppermost tributary would continue as the ascending lumbar vein in many cases. This variant was seen in 11 of 16 dissections. Figure 2 -- Diagram of the iliolumbar system with proximal and distal stems. This variant was seen in five out of 16 dissections. Figure 3 -- Diagram showing the ascending lumbar vein directly connecting with the common iliac vein.

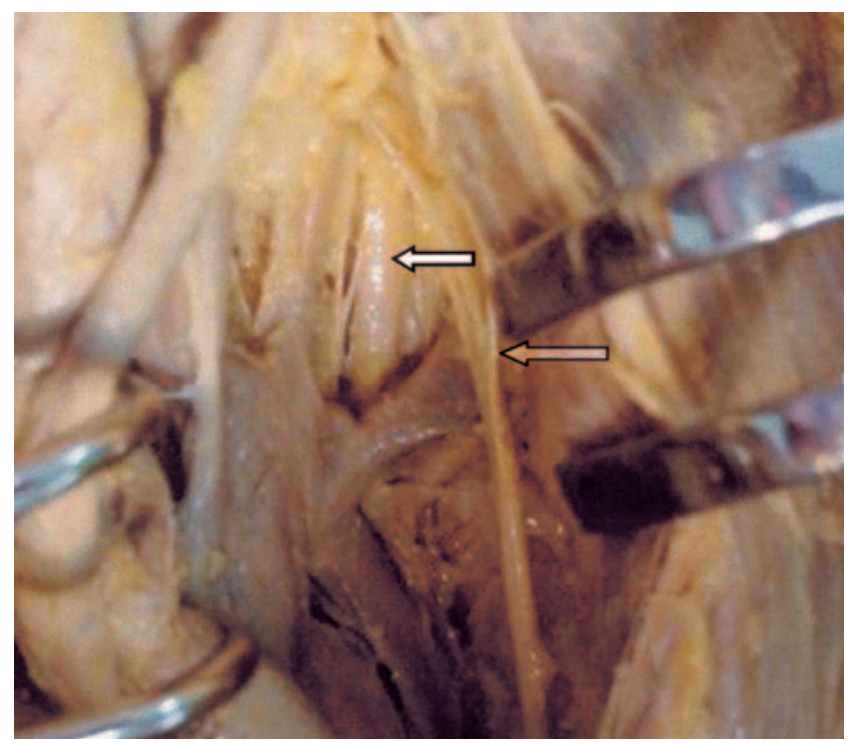

Fig. 4

Photograph showing the iliolumbar vein with a single short trunk and three tributaries. The obturator nerve lies superficial and lateral (shaded arrow) and the lumbosacral trunk deep (white arrow).

The mean width of the mouth of the iliolumbar vein was $1.07 \mathrm{~cm}(0.3$ to 2.8$)$, and the mean angle of obliquity of the vein with respect to the long axis of the common iliac vein was $79.54^{\circ}$ (50 to 110 ).

There was some variation in the tributaries draining into the main iliolumbar vein. In 11 dissections, two main tributaries drained into an iliolumbar trunk. In four, three or more tributaries drained into an iliolumbar vein. In one, a single trunk drained into the common iliac vein. The mean length of the stem in those with two or more draining tributaries was $1.6 \mathrm{~cm}(0.2$ to 2.5$)$. Three veins had short stems of $\leq 0.5 \mathrm{~cm}$. In 12 veins the most proximal tributaries continued as an ascending lumbar vein. In two dissections (1 left, 1 right), the equivalent of an ascending lumbar vein drained directly into the common iliac vein, just proximal to and separate from the iliolumbar stem (Figs 3 and 6). Importantly, in these last two, both the ascending lumbar and the iliolumbar veins were prone to avulsion on retraction medially.

In all dissections, the tributaries drained the iliacus and psoas muscles. There was a tributary draining the fifth lumbar vertebral body in ten veins and a small branch near the level of the transverse process and intervertebral foramen in two. These were difficult to follow, but may communicate with the internal vertebral venous plexus.

The immediate relationships of the iliolumbar vein were to the vertebral column medially and the great vessels superomedially. The iliacus muscle was deep to the vein. Superficially and laterally, the psoas muscle covered the lateral part of the vein and its tributaries. The most intimate relationship with the vein was the lumbar plexus, and in particular the obturator nerve and lumbosacral trunk (Figs 5 to 7).

In every dissection the obturator nerve crossed superficial to the iliolumbar vein. In all dissections, except one, the lumbosacral trunk passed deep to the vein (Fig. 5). In the other dissection, it passed superficial to it. The obturator nerve crossed the iliolumbar vein at a mean distance of $2.76 \mathrm{~cm}$ lateral to its site of entry into the common iliac vein. In four veins the nerve crossed very close to its mouth. In one of these it passed over the mouth of the vein and the lumbosacral trunk passed immediately deep to the axilla of the confluence between the iliolumbar and common iliac veins. In the remaining three veins, the nerve passed $0.8,0.9$ and $1.2 \mathrm{~cm}$ lateral to the mouth of the vein. In two the lumbosacral trunk passed close to and deep to the mouth of the vein $(0.8$ and $1.0 \mathrm{~cm})$ and in one, it passed superficially close to the mouth of the vein, as did the 


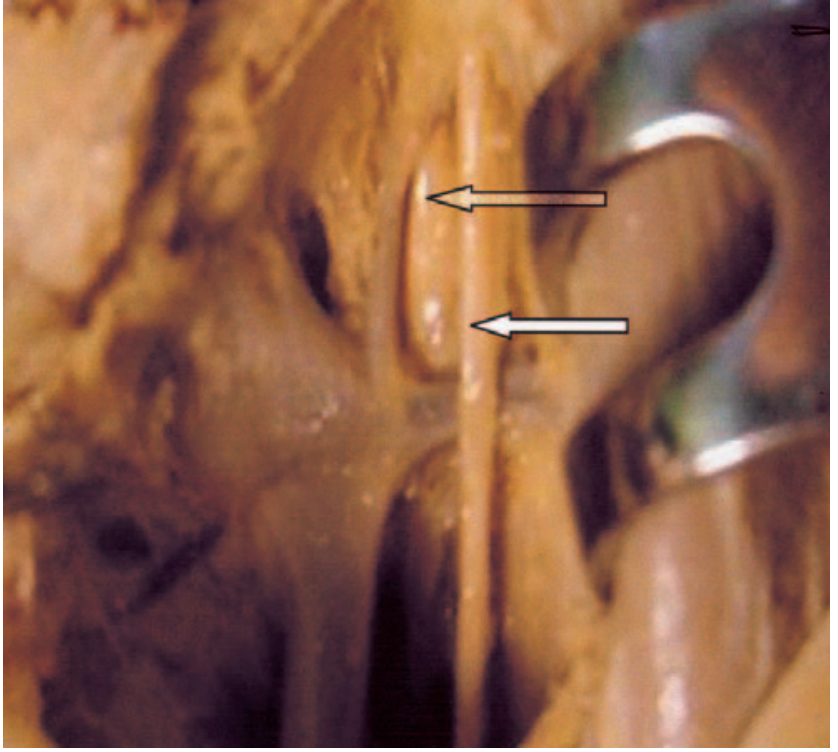

Fig. 5

Photograph showing a short single trunk vein with the obturator nerve (white arrow) and the lumbosacral trunk (shaded arrow) very close to its mouth.

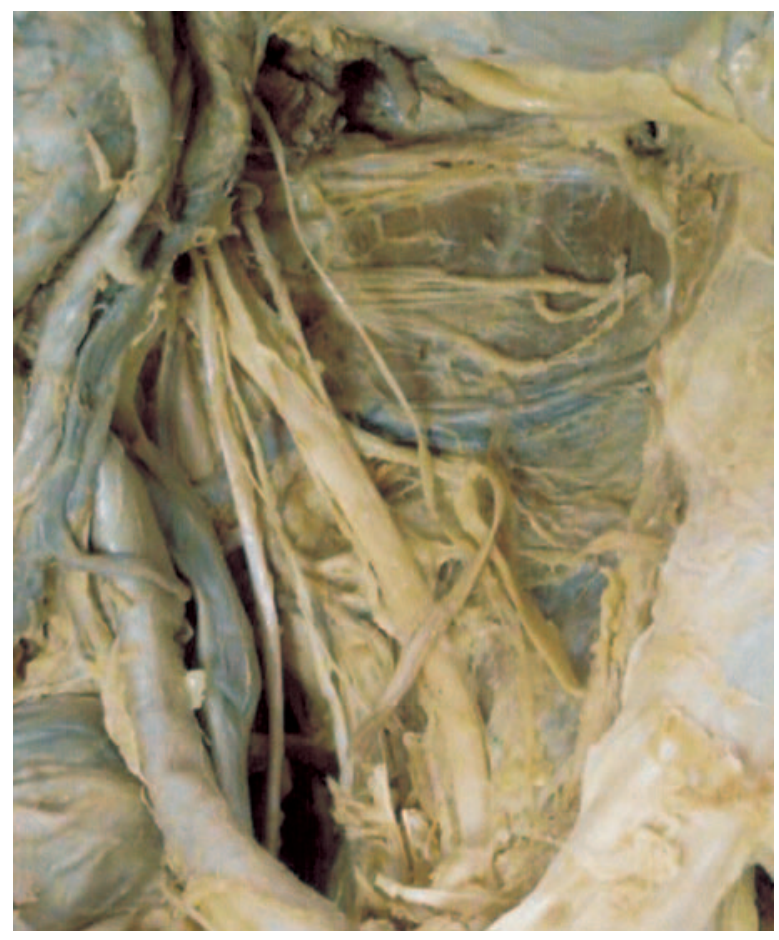

Fig. 7

The psoas muscle has been removed to show the relationship to the plexus and tributaries on iliacus.

obturator nerve $(1.4 \mathrm{~cm}$ laterally). In the remaining 12 veins, the lumbosacral trunk crossed the iliolumbar vein deep to the vein, at a mean distance of $2.5 \mathrm{~cm}$ lateral to the site of entry into the common iliac vein.

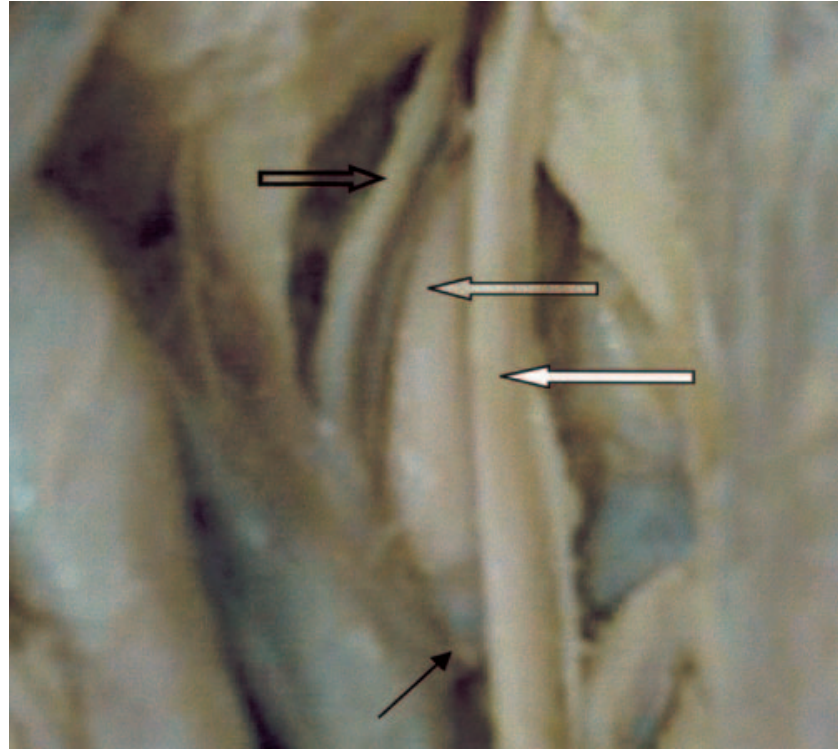

Fig. 6

Photograph showing the iliolumbar vein (line arrow) with the obturator nerve (white arrow) and the lumbosacral trunk (shaded arrow) at risk. There is an independently draining ascending lumbar vein (clear arrow).

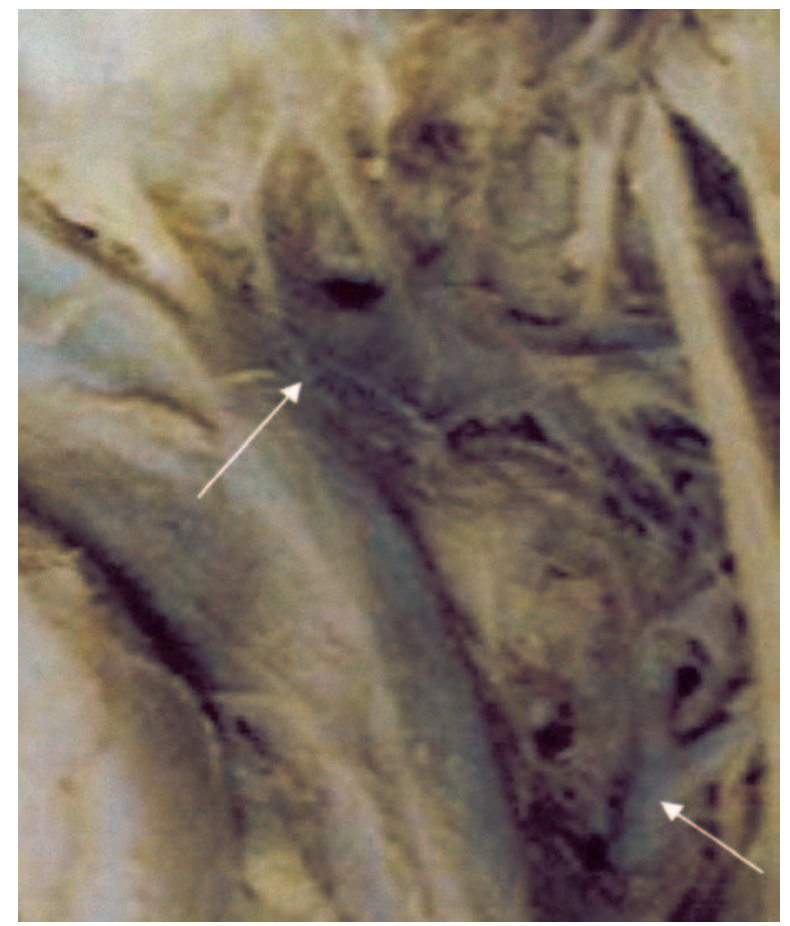

Fig. 8

Photograph showing the iliolumbar system with two draining stems, one proximal and one distal (white arrows).

The iliolumbar artery emerged from under the common iliac vein and accompanied the iliolumbar vein, lying deep to it. Unlike the vein, it was not unduly at risk during medial retraction of the great vessels. 


\section{Discussion}

Anterior exposure of the lumbosacral junction and the L4/ L5 disc space is used in the surgical treatment of tumours, infection, fractures, lumbar deformities and degenerative disc disease. ${ }^{1-7,16-19}$ Safe technique demands exposure and retraction of the great vessels which obscure the disc space. The iliolumbar vein, said to be one of the few veins draining into the common iliac vein, essentially acts as a tether, requiring ligature and division in order to allow safe exposure. ${ }^{1-7}$ Its avulsion allows a direction communication with a valveless venous system, and the possibility of massive haemorrhage. ${ }^{14-16}$ Apart from recommending control, there is little information on the iliolumbar vein in surgical and anatomical texts. ${ }^{1-13,17}$

Our dissections identified an iliolumbar system in every cadaver, and in most it drained the iliacus and psoas muscles, and fifth lumbar vertebra. Despite mixed nomenclature in some texts, ${ }^{1}$ we were able to demonstrate an iliolumbar vein separate from an ascending lumbar vein. Although often interconnected, the latter is a longitudinal structure ascending to drain into the azygos system. ${ }^{12,13,20}$

With a mouth of a mean width of $1 \mathrm{~cm}$ and entering the common iliac vein between 3 and $4 \mathrm{~cm}$ from the inferior vena cava, the iliolumbar vein is always at risk of avulsion on exposure of the disc space despite variations of length and angle of entry. Of great interest was the presence of a distal or accessory vein. This, however, was not vulnerable to avulsion, probably because of its greater distance from the inferior vena cava to its entry into the common iliac vein. We feel that it can probably be ignored at surgery, but with the qualification that it should be ensured that an independently draining ascending lumbar vein is not mistaken for the proximal or main iliolumbar vein, since, when this occurred, both the ascending lumbar and main iliolumbar veins tore on retraction. ${ }^{12,20}$ An independently draining ascending lumbar vein can be recognised by the close proximity of its entry point to that of the iliolumbar vein and its more longitudinal orientation. In a system with a true main and accessory iliolumbar vein, the mean distance between the two was about $3 \mathrm{~cm}$ and both ran more horizontally (Figs 2, 3, 6 and 8).

There were several variations in the tributaries of the iliolumbar vein. The presence of multiple tributaries may be hazardous. If the lateral ligature does not include all the tributaries, massive haemorrhage could ensue. Similarly, the variation in the length of the main stem may make ligature difficult, particularly when the vein is short with virtually no stem (Figs 4 and 5). The short stem may also increase the risk of a sidewall injury to the common iliac vein. ${ }^{7}$

The intimate relationship of the iliolumbar vein to the obturator nerve and lumbosacral trunk of the lumbar plexus has not been previously described. The iliolumbar vein ran between the two nerves in every dissection except one. The obturator nerve always passed superficial to the vein and the lumbosacral trunk almost always passed deep to it. Often, the nerves crossed near the mouth of the vein. Both of these nerves could be accidentally caught in ligatures with the lateral portion of vein if the vein was not adequately exposed. In the event of inadvertent haemorrhage, the nerves could easily be damaged by clamps or diathermy. Due to the risk of damaging the common iliac vein or these nerves, we feel that diathermy should not be used to control the iliolumbar vein.

Our study confirmed that there are variations in the anatomy of the iliolumbar vein. Whatever the variation in size, position, tributaries or number of veins, all were vulnerable to avulsion on retraction of the great vessels. The findings of the relationship to the obturator nerve and lumbosacral trunk further highlight the need for proper exposure of this vein before ligature to allow safe surgical exposure of the anterior lumbar spine.

No benefits in any form have been received or will be received from a commercial party related directly or indirectly to the subject of this article.

\section{References}

1. Crock HV. A short practice of spinal surgery. Second ed. Wien, etc: Springer Verlag, 1993:76-8,86-8.

2. Hodgson AR, Wong SK. A description of a technique and evaluation of results in anterior spinal fusion for deranged intervertebral disk and spondylolisthesis. Clin Orthop 1968;56:133-62.

3. Leong JCY, Hooper G, Fang D, Chun SY. Disc excision and anterior spinal fusion for lumbar disc protrusion in the adolescent. Spine 1982;7:623-6.

4. Tsuji H. Comprehensive atlas of lumbar spine surgery. St. Louis, etc: Mosby-Year Book, 1991:236-7.

5. An HS. Principles and techniques of spine surgery. Baltimore: William and Wilkins, 1997:57.

6. Inoue S, Watanabe $\mathbf{T}$, Hirose $\mathbf{A}$, et al. Anterior discectomy and interbody fusion for lumbar disc herniation: a review of 350 cases. Clin Orthop 1984;183:22-31.

7. Watkins RG. Surgical approaches to the spine. Wien, etc: Springer Verlag, 1983:106-7.

8. Esses SI, Botsford DJ. Surgical anatomy and operative approaches to the sacrum. In: Frymoyer JW ed. The adult spine: principles and practice. Vol 2. New York: Raven Press, 1991:21-3-4.

9. Sinnatamby C. Last's anatomy regional and applied. Tenth ed. Edinburgh: Churchill Livingstone, 1999:270.

10. Crock HV, Yoshizawa H. The blood supply of the vertebral column and spinal cord in man. New York, etc: Springer-Verlag, 1977:45-7.

11. Crock HV. An atlas of vascular anatomy of the skeleton and spinal cord. London: Martin Dunitz, 1996:127-8.

12. Agur AM, Lee MJ. Grant's atlas of anatomy. Tenth ed. Philadelphia, etc: JB Lippincott Company 1999:77,164.

13. Gabella G. Veins of the abdomen and pelvis. In: William PL ed. Gray's anatomy. Thirty-eighth ed. Edinburgh: Churchill Livingstone, 1995:1599-1601.

14. Baker JK, Reardon PR, Reardon MJ, Heggeness MH. Vascular injury in anterior lumbar surgery. Spine 1993;18:2227-30.

15. Stambough JL, Simeone FA. Vascular complications in spine surgery. In: Herkowitz HN, ed. Rothman-Simeone, the spine. Vol 2, Fourth ed. Philadelphia: WB Saunders Company, 1999:1718-19.

16. Kozak JA, Heilman AE, O'Brien JP. Anterior lumbar fusion options: technique and graft materials. Clin Orthop 1994;300:45-51.

17. Harmon PH. A simplified surgical technic for anterior lumbar diskectomy and fusion; avoidance of complications; anatomy of the retroperitoneal veins. Clin Orthop 1964;37:130-44.

18. Hodgson AR, Stock FE. Anterior spine fusion for the treatment of tuberculosis of the spine. J Bone Joint Surg [Am] 1960;42-A:295-309.

19. Kostuik JP. Anterior fixation for burst fractures of the thoracic and lumbar spine with or without neurological involvement. Spine 1988;13:286-93.

20. Arthornthurasook A, Gaew-Im K. Study of ascending lumbar and iliolumbar veins. Spine 1987;12:70-2. 